\title{
СПЕЦИФИКА ПРОЯВЛЕНИЯ ТРЕВОЖНОСТИ У ДЕТЕЙ ДОШКОЛЬНОГО ВОЗРАСТА С НАРУШЕНИЯМИ ДВИГАТЕЛЬНОЙ ФУНКЦИИ
}

\section{THE SPECIFICS OF THE MANIFESTATION OF ANXIETY IN PRESCHOOL CHILDREN WITH IMPAIRED MOTOR FUNCTION}

T. Gutova

Yu. Pidshmorga

Summary: The article analyzes the features of the manifestation of the level of anxiety in children with motor impairments in comparison with children with normal development. The reasons that increase the level of anxiety in children with cerebral palsy were revealed: not only physical limitations leading to the social isolation of the sick child's personality, but also an incorrect attitude towards such a child on the part of family members and the immediate environment. Thus, the child's feeling of his own uselessness and uselessness, both physical and social, naturally increases his level of anxiety, irritability and even hostility towards the outside world. The ways of solving this problematic situation are proposed: psychological counseling of families with a child with impaired motor functions, creating in such a child a sense of social value and equality, compensating for his physical imperfections.

Keywords: anxiety, diagnosis of anxiety, impaired motor function, infantile cerebral palsy.
Гутова Тамара Сергеевна

К.псх.н., дочент, Кубанский государственный медицинский университет, Краснодар

zhurzhu@mail.ru

Пидиморга Юлия Владимировна

К.культурологии, Кубанский государственный медицинский университет, Краснодар ypidshmorga@yandex.ru

Аннотация: В статье проанализированы особенности проявления уровня тревожности у детей с нарушениями двигательной функции в сравнении с детьми, имеющими нормальное развитие. Выявлены причины, повышающие уровень тревожности у детей, больных ДЦП: не только физические ограничения, приводящие к социальной изоляции личности больного ребенка, но и некорректное отношение к такому ребенку со стороны членов семьи и ближайшего окружения. Таким образом, формируемое у ребенка чувство собственной бесполезности и ненужности, притом как физической, так и социальной, закономерно повышают у него уровень тревожности, раздражительности и даже враждебности по отношению к внешнему миру. Предложены пути решения данной проблемной ситуации: психологическое консультирование семей, имеющих ребенка с нарушением двигательных функций, создание у такого ребенка чувства социальной полноценности и равенства, компенсирующих его физические несовершенства.

Ключевые слова: тревожность, диагностика тревожности, нарушение двигательной функции, детский церебральный паралич.

очень многоаспектна, так как нарушения касаются не только двигательных, но и мыслительных, речевых и коммуникативных аспектов их деятельности. Отмечается так же проблема самоидентификации личности, снижении самооценки, ослабление волевых усилий, угасание психо-эмоциональной сферы $[1,3]$.

С целью выявления специфики проявления специфических проявлений тревожности у детей старшего дошкольного возраста, имеющих двигательные патологии при их сравнении с детьми без отклонений, авторами было организовано исследование в виде проведения экспериментальной диагностики. В данную программу вошел анализ медицинских документов и графических продуктов наблюдаемых детей - рисунков, а так же анкеты-опросники и проективные тесты.

Предлагаемые к выполнению задания были подготовлены с учетом возрастных особенностей испытуемых, сопровождались подробной инструкцией к выполнению и содержали демонстративное подкрепление для более точного выполнения. Высокопрофессиональ-

Коррекционная работа с детьми, больными ДЦП, 
ная подготовка исследователей позволила установить прочный психо-эмоциональный контакт с испытуемыми, гарантирующий их вовлеченность и настрой на продуктивную работу с исследователем. Таким образом, отклонений предложения принять участия в исследовании выявлено не было.

Обследование детей с двигательными нарушениями проводилось в кабинете социального педагога на базе ГБУЗ «Краевой детский центр медицинской реабилитации» Министерства здравоохранения Краснодарского края с отрывом от проведения занятий. Эмпирическое исследование проходило в два этапа, по 20-25 минут каждый. В свою очередь, обследование детей с нормой развития проводилось в кабинете психолога в городе Крымске в МАДОУ Детском саду № 3 «Росинка». Психологическая диагностика проводилась в специально подготовленной для этого комнате, без присутствия посторонних, что поддерживало чистоту проводимого эксперимента и гарантировало исключение участия сторонних лиц - воспитателей, психологов, родителей на детей в процессе проведения эксперимента. Данная работа строилась на всестороннем учете методических требований, описывающих правомерность психологического исследования. Игровой формат и эмоциональный и зрительный контакт экспериментатора с наблюдаемыми детьми обеспечивали атмосферу сотрудничества и доверия между участниками эксперимента.

На протяжении всего исследования экспериментатор проявлял высокий уровень эмпатии по отношению к испытуемым детям, хвалил их за вовлеченность и искренность в процессе участия в эксперименте. Последовательность демонстрации изображений на картинках определялась рамками используемой методики. Не применяемым в данный момент стимулирующий материал хранился вне поля внимания участников эксперимента, чтобы не происходило рассредоточения внимания детей на несколько картинок одновременно.

Отвлечение на посторонние манипуляции, не предусмотренные диагностической методикой, отслеживались и исключались экспериментатором. Экспериментатор в процессе исследования придерживается политики невмешательства в процесс расположения ребенком изображений по приоритетности (при конструировании «паровозика»).

Для испытуемых в ходе эксперимента для детей с нарушением двигательных функций были созданы все необходимые психологические и средовые условия, способствующие их комфортному участию в эксперименте. Учитывались также рекомендации ортопеда и невропатолога посредством предварительного анализа медицинских карт детей. В течение всего эксперимента велось наблюдение за состоянием мышечного тонуса испытуемых, при необходимости исследование носило сессионный характер в зависимости от степени утомляемости испытуемого.

Рассмотрим результаты комплексного обследования по каждой методике более подробно.

Уровень тревожности дошкольников с ДЦП, связанный с эмоциональной приспособленностью к социальным ситуациям, с характером взаимоотношений со сверстниками и взрослыми в семье и в коллективе, авторы изучали с помощью применения методики, направленной на диагностику уровня тревожности (предложенного авторами В. Амен, М. Дорки, Р. Тэммпл) [5]. Детский тест тревожности позволил собрать результаты, описывающие специфику состояний тревожности у детей старшего дошкольного возраста, страдающих нарушениями двигательной функции, в сравнении с аналогичными проблемами у детей в детском возрасте.

Аналитическая работа подразумевала отработку собранных в ходе исследования данных количественным (выявление общих закономерностей уровня тревожности у испытуемых обеих групп) и качественным (вычисление индекса тревожности - ИТ - как процентного отношения эмоционально негативного выбора к количеству изображений) способами.

Высокий уровень тревожности (ИТ выше 50\%) отмечается у 33 участников эксперимента в группе №1. Такой показатель проявляется в высоком уровне конфликтности в процессе коммуникации с ровесниками, психоэмоциональной нестабильностью и высоким уровнем раздражительности. Условия семейного воспитания таких детей оцениваются как неблагоприятные, на каждого 4-го испытуемого приходился один родитель-инвалид; у 7 испытуемых в составе семьи отмечается наличие младшего брата (сестры) без патологий здоровья. Средний уровень тревожности (ИТ в диапазоне 20-50\%) выявлен у 15 испытуемых (30\% от общего числа участников эксперимента), имеющих нарушение двигательных функций, которое отягощает процесс социальной адаптации для таких детей. Только 2 человека (4\%) имеют низкий уровень тревожности, то есть проблемы с состоянием здоровья не мешают им гармонично развиваться.

В экспериментальной группе №2 отмечается более позитивный результат, характеризующий уровень тревожности испытуемых. У 6 человек (а это около 13\% от общего числа испытуемых) выявленный уровень тревожности описывается как низкий - ИТ менее 20\%. У 39 человек отмечается средний уровень тревожности (77\% испытуемых). И только 5 человек характеризуются достаточно высоким уровнем тревожности (10\% от общего числа испытуемых). Отсюда следует, что средним уровнем тревожности описывается состояние большинства 
испытуемых детей: ИТ колеблется в диапазоне 20-50\%, тогда как средним уровнем тревожности описывается состояние $30 \%$ испытуемых с ДЦП.

у испытуемых группы №1 повышенный уровень тревожности отмечается чаще, ориентировочно у $67 \%$ испытуемых. На контрасте с приведенными данными, в группе №2 такой уровень отмечается лишь у 10\% испытуемых. Сравнительный анализ тревожности у детей с ДЦП и детей с нормальным развитием представлен на рисунке №1.

Распределение старших дошкольников в зависимости от уровня тревожности

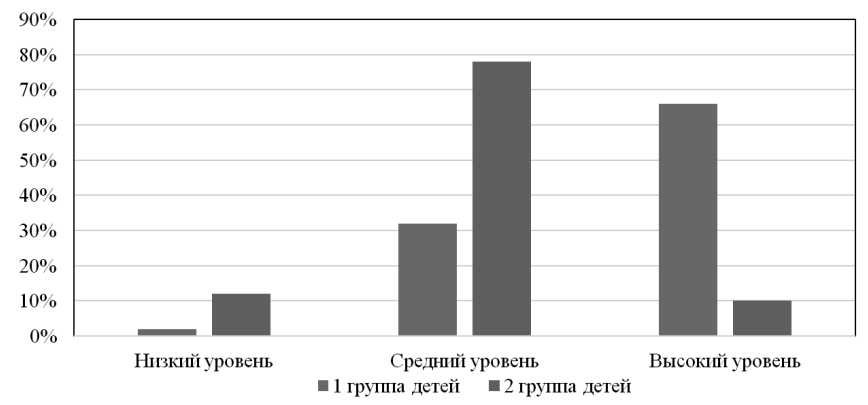

Рис. 1. Распределение старших дошкольников 1 и 2 экспериментальных групп по уровню тревожности (\%)

Выраженность степени позитивного и негативного психического состояния дошкольников с ДЦП авторы изучали с помощью методики «Паровозики», предложенной С.В. Велиевой [5]. В таблице 1 представлены краткие результаты методики.

Таблица 1.

Выраженность тревожности дошкольников с ДЦП по методике С.В. Велиевой «Паровозики»

\begin{tabular}{|l|c|c|}
\hline Уровень тревожности & 1 (количество детей) & 2 (количество детей) \\
\hline Высокий & 36 & 5 \\
\hline Средний & 12 & 34 \\
\hline Низкий & 2 & 4 \\
\hline $\begin{array}{l}\text { Позитивное } \\
\text { психическое состояние }\end{array}$ & - & 7 \\
\hline
\end{tabular}

Старшие дошкольники первой экспериментальной группы демонстрировали в ходе эксперимента показатели как высокого уровня тревожности, так и низкого. Большая часть испытуемых (72\% - 36 чел.) в первой группе проявляют высокий уровень тревожности, характеризующийся как негативное психическое состояние высокой степени. В этой подгруппе исследуемых внутрисемейное воспитание характеризовалось неблагоприятными и удовлетворительными условиями социального и психологического взаимодействия. У некоторых испытуемых (24\% - 12 чел.) первой экспериментальной группы отмечался средний уровень тревожности (негативное психическое состояние средней степени). И лишь у 4\% дошкольников (2 чел.) наблюдался низкий уровень тревожности, позволяющий этим детям успешно адаптироваться в различных ситуациях. Схематично это можно изобразить следующим образом (рис. 2).

По результатам проведенного исследования в экспериментальной группе №2 уровень тревожность испытуемых характеризуется как более низкий. Он свойственен четырем испытуемым, что составляет $8 \%$ от общего числа участников эксперимента.

Показатели среднего уровня тревожности, который необходим ребенку для эффективной адаптации в социальной среде, преобладали в данной группе и наблюдались у $68 \%$ дошкольников (34 чел.). Высокий уровень тревожности наблюдался у $10 \%$ детей (5 чел.). Схематично это можно изобразить следующим образом (рис. 2-3).

Тест «Дом. Дерево. Человек» (ДДЧ) Дж. Бака [5], позволяющий выявить следующие симптомокомплексы: чувство незащищенности, тревожность, неуверенность в себе, чувство неполноценности, враждебность к окружающим, наличие конфликтной (фрустрирующей) ситуации в жизни ребенка, трудности в общении и установлении контактов, депрессивные тенденции. По завершению работы над первым рисунком, испытуемого просили изобразить дерево, а после - еще и человека. Условия работы были таковыми, что задание по изображению заданных образов озвучивалось сразу, а не по мере выполнения каждого из 3-ех рисунков. В процессе выполнения данного задания, психолог осуществляет непрерывное наблюдение за испытуемым, отмечая для себя важные аспекты его поведения.

Для реализации методики ДДЧ использовался светлый и просторный логопедический кабинет, в котором отсутствовали какие бы то ни было необычные, способные отвлечь ребенка, предметы - книги, рисунки, картинки, фигуры.

Кратко результаты применения данной методики представлены на рисунках 4 и 5.

Старшие дошкольники первой экспериментальной группы демонстрировали в ходе эксперимента показатели преимущественно высокого уровня тревожности. Большая часть испытуемых (72\% - 36 чел.) в первой группе проявляют высокий уровень тревожности, у некоторых испытуемых (22\% - 11 чел.) первой экспериментальной группы отмечался средний уровень тревожности. И лишь у $6 \%$ дошкольников (3 чел.) наблюдался низкий уровень тревожности.

Во второй экспериментальной группе показатели уровня тревожности были значительно ниже. У $14 \%$ 


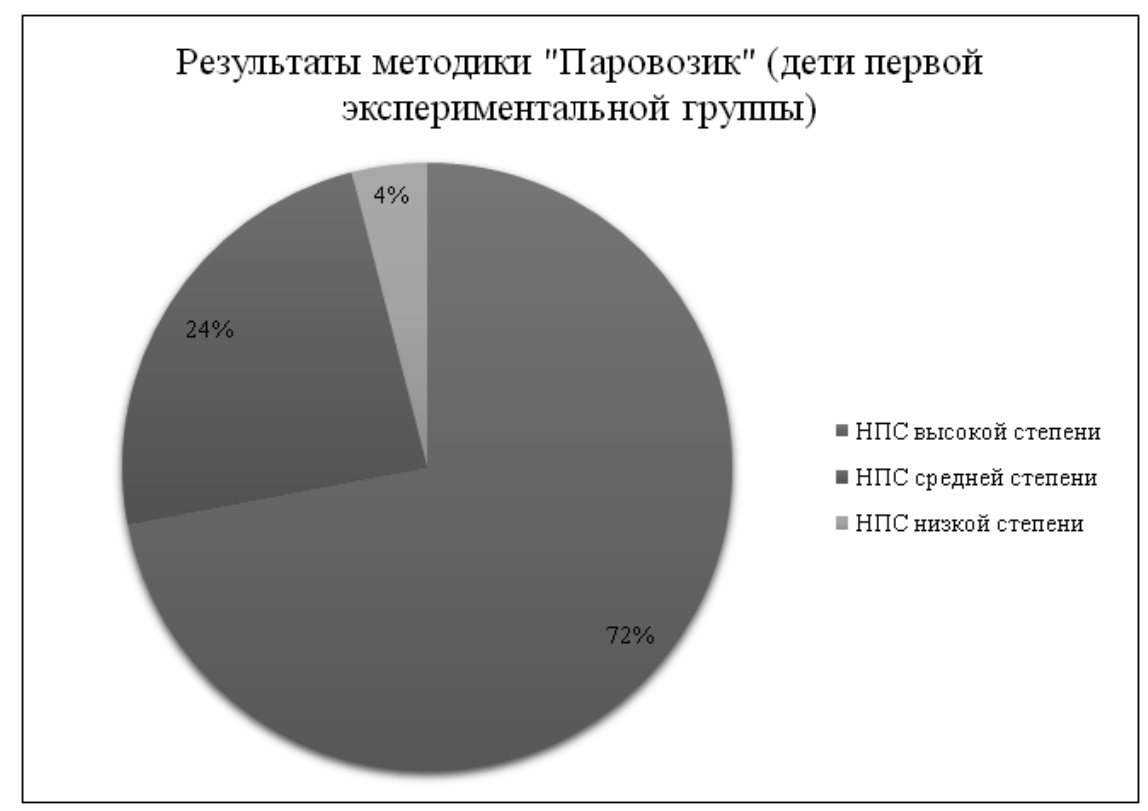

Рис. 2. Результаты методики «Паровозик» С.В. Велиевой (дети с двигательной патологией)

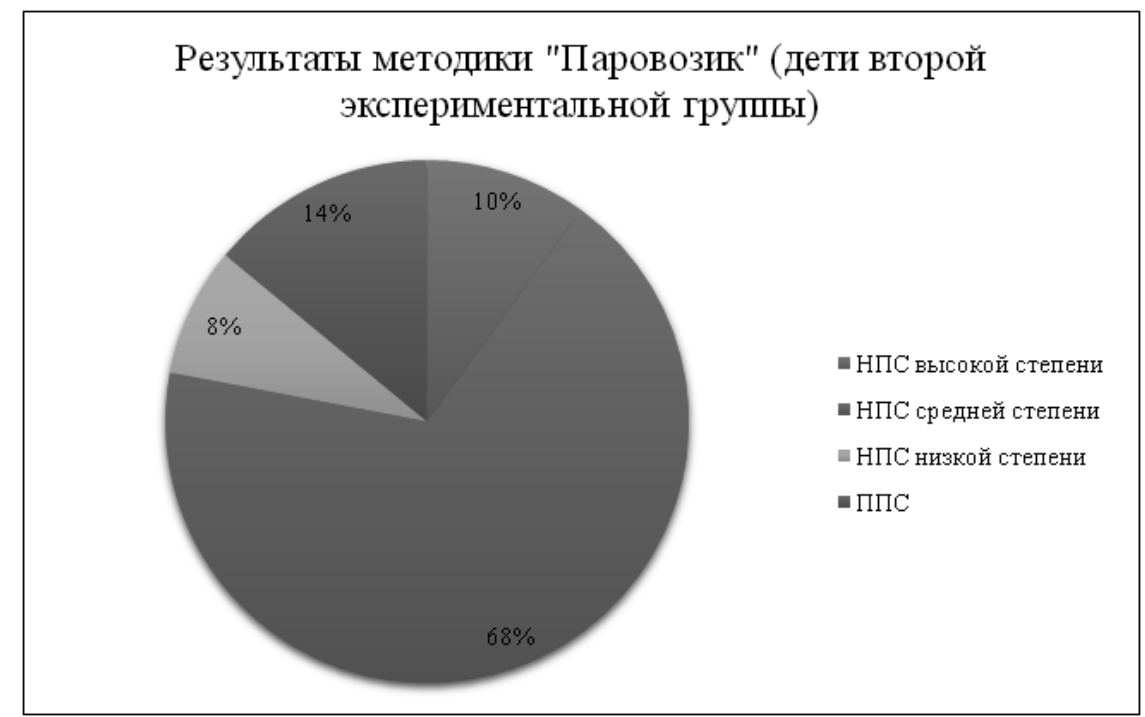

Рис. 3. Результаты методики «Паровозик» С.В. Велиевой (дети с нормальным развитием)

обследуемых тревожность не была выявлена (7 чел.). Низкий уровень тревожности был отечен у $12 \%$ детей (6 чел.). Показатели среднего уровня тревожности преобладали в данной группе и наблюдались у $64 \%$ дошкольников (32 чел.). Высокий уровень тревожности наблюдался у $10 \%$ детей (5 чел.).

Анализируя полученные в ходе проведения психологической диагностики детей старшего дошкольного возраста данные можно сделать вывод о том, что между первой и второй группой существуют достоверные различия по всем представленным методикам.

В первой экспериментальной группе было 50 детей с двигательной патологией, во второй группе 50 детей с нормой развития, которые имели высокий, средний и низкий уровень тревожности.

\section{Выводы.}

В заключении отметим, что основным результатом исследования авторы отмечают специфические формы проявления тревожности у детей, больных ДЦП. К ним можно отнести: эмоциональную напряженность и нестабильность, низкий уровень решительности и активности, боязливость, раздражительность, повышенный уровень беспокойства. Среди причин, объясняющих данную специфику, авторами были отмечены не только физические ограничения и сложности социального взаимодействия детей с ДЦП с представителями раз- 


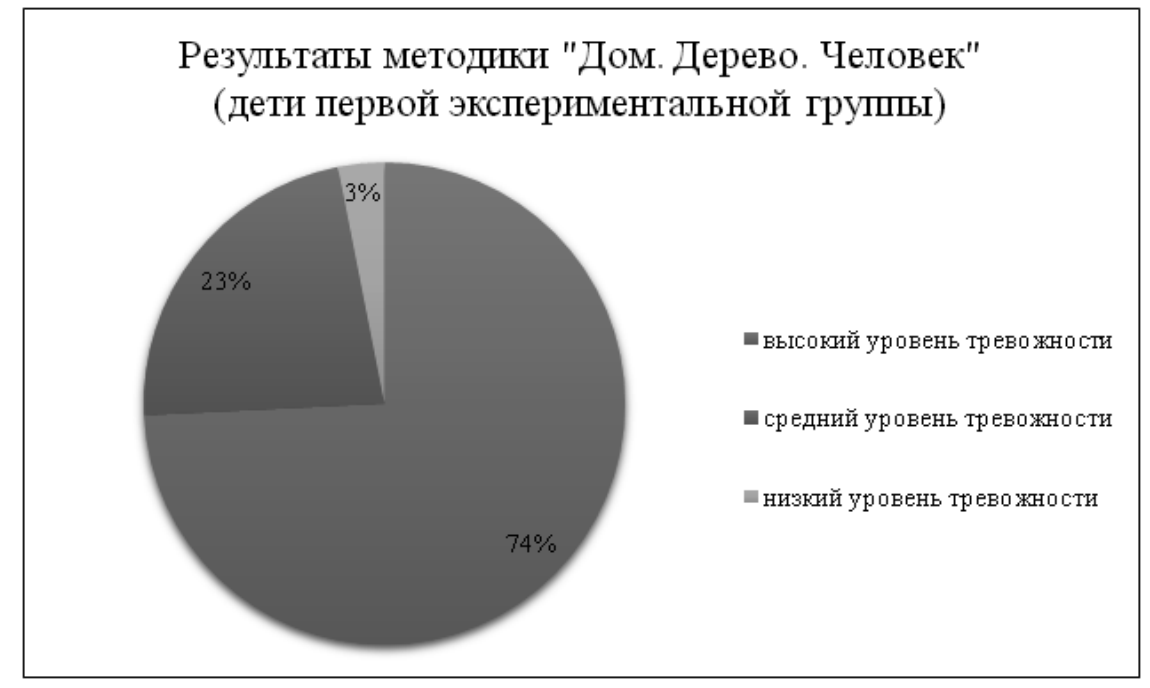

Рис. 4. Результаты методики «ДДЧ» (дети с нарушением двигательной сферы)

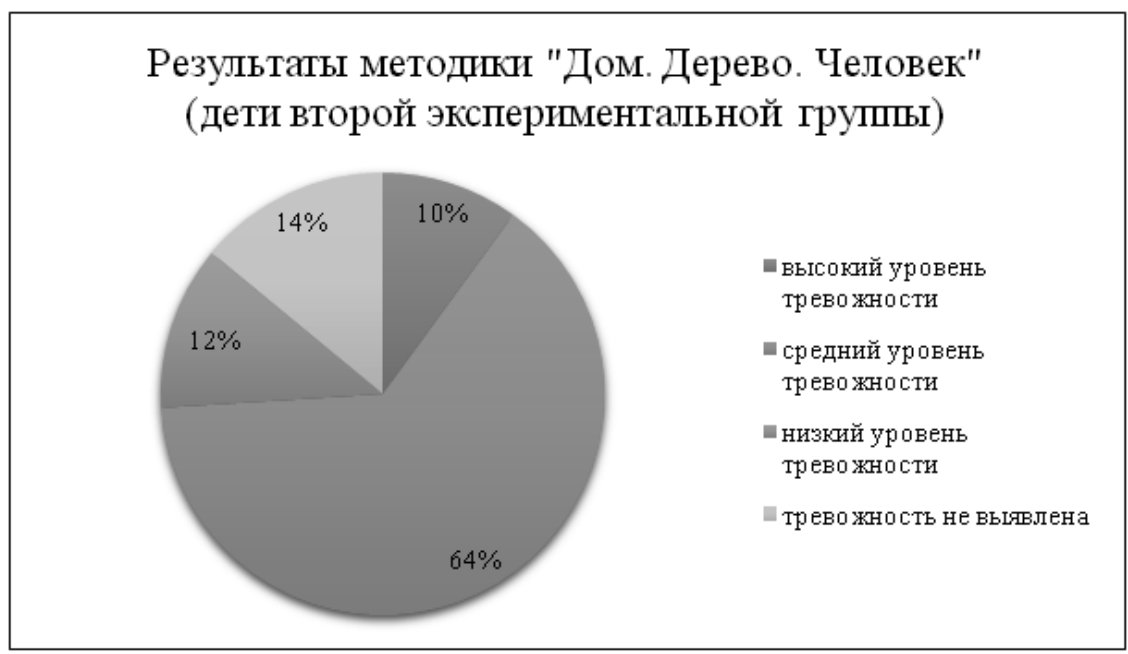

Рис. 5. Результаты методики «ДДЧ» (дети с нормальным развитием)

личных социальных групп, но и сложности внутрисемейной ситуации: сами родители не могут обеспечить комфортный режим взаимодействия с больным ребенком. Применение в практике семейного воспитания эф- фективных методов психологичной поддержки с целью выработки у ребенка чувства собственной важности, уважения, принятия себя, компенсируют его физические несовершенства.

\section{ЛИТЕРАТУРА}

1. Колесникова Г.Ю. Субъективный мир личности с нарушениями двигательной сферы: дис. ... канд. психол. наук: 19.00.10 / Г.Ю. Колесникова. М.: РГБ, 2012. 189 c.

2. Колесникова Г.Ю. Изучение когнитивного и эмоционально-ценностного компонентов Я-концепции молодых людей с нарушением двигательной сферы // Психология и педагогика: методика и проблемы практического применения. 2016. № 49-1. С. 45-50.

3. Овчинникова И.В., Пчелинцева Е.В. Особенности когнитивного и эмоционально-ценностного компонентов Я-концепции у лиц с нарушениями функций двигательной сферы на этапе ранней реабилитации // Вестник Ивановской медицинской академии. 2016. Т. 21. № 3. С. 14-19.

4. Калижнюк Э.С. Психические нарушения при ДЦП. Киев: Высшая школа. 1987. 309 с.

5. Семаго Н.Я., Семаго М.М. Теория и практика психического развития ребенка. Дошкольный и младший школьный возраст. - СПб.: Речь, 2006. -384 с.

( Гутова Тамара Сергеевна (zhurzhu@mail.ru), Пидшморга Юлия Владимировна (ypidshmorga@yandex.ru). 